\title{
Study on Diversity of Undergrowth Plant Community in Cibagou Nature Reserve
}

\author{
Wei Wang, Zhen Xing*, Wenbo Li, Xiaolin Yang \\ Xizang Agriculture and Animal Husbandry College, Nyingchi, China \\ Email: ${ }^{*} 470382094 @ q q . c o m$
}

How to cite this paper: Wang, W., Xing, Z., Li, W.B. and Yang, X.L. (2017) Study on Diversity of Undergrowth Plant Community in Cibagou Nature Reserve. American Journal of Plant Sciences, 8, 2149-2158. https://doi.org/10.4236/ajps.2017.89144

Received: July 23, 2017

Accepted: August 7, 2017

Published: August 10, 2017

Copyright $\odot 2017$ by authors and Scientific Research Publishing Inc. This work is licensed under the Creative Commons Attribution International License (CC BY 4.0).

http://creativecommons.org/licenses/by/4.0/

(c) (i) Open Access

\begin{abstract}
The forest community diversity along the altitudinal gradient was analyzed in the Cibagou National Nature Reserve. Results showed that the forest types of Cibagou Gorge could be divided into six types: Castanopsis hystrix forest; camphor and acer mixed forest, blue Japanese oak broad-leaved mixed forest, blue Japanese oak forest, Populus simonii mixed forest; Quercus aquifolioides forest. The total coverage of undergrowth vegetation altitude was the lowest at $1749 \mathrm{~m}$, only $30 \%$, and plant species numbers in the sample was only 5 . The total coverage of the plant was the highest at $2327 \mathrm{~m}$ altitude, the value was $95 \%$, and the number of species in experiment plot was 14 . The species richness of Margalef increased first and then decreased with the increase of altitude gradient at $1749 \mathrm{~m}$ to $2880 \mathrm{~m}$, and the Shannon-wiener species diversity index increased, but the difference was not significant, Pielou species evenness and Sheldon species evenness index decreased first and then increased with altitude.
\end{abstract}

\section{Keywords}

Cibagou National Nature Reserve, Undergrowth Plant, Plant Diversity

\section{Introduction}

Study of biological diversity has long been the concern of the ecology. Plant species diversity and species richness is the comprehensive reflection of the uniform distribution, the difference can not only reflect the characteristics of plant communities in composition, structure, characteristics of spatial and time characteristics, but also reflect the plant community [1] [2]. Forest is one of the most important ecological systems of land types, the species diversity and spatial pattern has long been one of the hotspots in the research, forest vegetation as an important part of forest ecosystem, plays an important role in maintaining the 
function of forest ecosystems, forest ecosystems to maintain their stability [3] [4] [5].

Cibagou nature reserve is located in the southeast of Tibet, and was typical Alpine Canyon terrain. Because of its unique geographical location and wellpreserved primary forest ecosystem characteristics, natural academic research has been attracted attention of researchers in different research field for longtime, but limited by traffic infrastructure, only few researches has been conducted over the past few decades, such aslarge animal species research [6] [7] [8], insect classification research [9], study on the Characteristics of Actinomycetes [10]. The investigation of plant resources was only carried out the part of plant species investigation, and the plant species community diversity research has not been conducted and analyzed. In this study, we investigated the vegetation under different elevation gradients in the Cibagou National Nature Reserve, and analyzed species diversity by the commonly analysis method. The aim was to provide some references for the comprehensive management of vegetation, the protection and development of biodiversity in Cibagou Nature Reserve.

\section{Materials and Methods}

\subsection{Natural Geography Characters}

The Cibagou Nature Reserve is located in the southeastern part of the QinghaiTibet Plateau in the southeastern part of the Tibet Autonomous Region. It is the intersection of the Himalayas and the Hengduan Mountains. The geographical coordinates are North latitude $28^{\circ} 34^{\prime}-29^{\circ} 07^{\prime}$, East latitude $96^{\circ} 52^{\prime}-97^{\circ} 10^{\prime}$, attitude $2500 \mathrm{~m}$. Cibagou Nature Reserve area annual precipitation of more than $1000 \mathrm{~mm}$, the average annual temperature was range $10^{\circ} \mathrm{C}-20^{\circ} \mathrm{C}$, the average annual humidity was range $60 \%$ to $70 \%$, frost-free period was more than $200 \mathrm{~d}$. Cibagou Nature Reserve is $76 \mathrm{~km}$ long from north to south and $33 \mathrm{~km}$ from east to west. The total area is about $1 \times 10^{5} \mathrm{hm}^{2}$. The forest area of $5 \times 10^{4} \mathrm{hm}^{2}$, forest coverage rate of up to $54.6 \%$, the total forest volume was about $1.6 \times 10^{8} \mathrm{~m}^{3}$. According to the forest (vegetation) type classification system can be divided into mountain subtropical evergreen broad-leaved forest, mountain deciduous broadleaved forest, temperate hardwood evergreen oak forest, mountain temperate pine forest, mountain Berlin, subalpine deciduous coniferous forest, subalpine Dark coniferous forest, shrub, meadow.

\subsection{Research Methods}

\subsubsection{Sample Selection Settings, and Forest Plant Community Survey}

The experiment was carried out in the Cibagou Nature Reserve in July 2016, walked about $30 \mathrm{~km}$ along the cibagou gully. The vicinity of the Ciba Ditch Ecological Protection Station is the end of the survey. In the case of obvious division of forest vegetation, select the appropriate sample to investigate, set two $10 \mathrm{~m} \times$ $10 \mathrm{~m}$ quadrats, respectively, in the sample four corners and the center set $2 \mathrm{~m} \times$ 
$2 \mathrm{~m}$ small sample (a total of 10) for the investigation of forest Under vegetation. The height, coverage, quantity and other information of understory plant vegetation were determined according to the types of plant species, and the important values of different plant species were calculated. The calculation formula was as follows [11]:

The important value of a plant species IV

$=($ relative height + relative coverage + relative degree $) / 3$

Relative height = height of individual plant species/sum of all the plant species height

Relative coverage

$=$ Coverage of individual plant species/sum of all plant species coverage

Relative degrees $=$ Numbers of individual plant species/sum of all plant species numbers

\subsubsection{Plant Diversity Calculation Method}

The plant community was systematically analyzed by species richness, species diversity and species uniformity.

Margalef Richness Index: $D=(S-1) / \ln N$

Menhinick Richness Index: $D=\ln S / \ln N$

Shannon-wiener diversity index: $H^{\prime}=-\sum P i * \ln P i$

Simpion diversity index: $H^{\prime}=1-\sum P i * \ln P i$

Pielou evenness index: $J S w=\left(-\sum P i * \ln P i\right) / \ln S$

Sheldon Evenness Index: $E s=\left[\exp \left(-\sum P i * \ln P i\right)\right] / S$

where $S$ is the number of species in the sample, $N$ is the number of all species in the sample, and $P i$ is the important value of species $i$.

\section{Result}

\subsection{Analysis of Plant Community Composition and Important Value under Different Altitudinal Gradients}

The difference of plant composition in understory reflects the habitat condition of forest land [12]. According to the investigation results, we can divide the Cibagou forest types were divided into Castanopsis forest, mixed forest, Acer green broad-leaved forest, oak forest, poplar and birch mixed forest, Quercusaquifolioide forest with 6 species. Can be seen from Table 1, at different altitudes in the forest, understory plant species have obvious differences, at an altitude of 1749 m Castanopsis forest, understory plant coverage was lowest, only 30\% species numbers were only 3 , the highest importance value was 0.518 for Lepisorusthunbergianus, followed by Campylotropis macrocarpa and Cymbidium hookerianum, important values were 0.255 and 0.172 respectively; at an altitude of $2327 \mathrm{~m}$ oak forest, understory plant total coverage was reached 95\%, species number was 14, the highest importance value for the Impatiens linghziensis and Galium aparine Linn. var. echinospermum.

At an altitude of $1960 \mathrm{~m}$ mixed forest, plant community coverage was $80 \%$ and plots in the number of species was 13 , significant higher values of the 
Table 1. The important values of plant species in different forest stands at different altitudes in Cibagou.

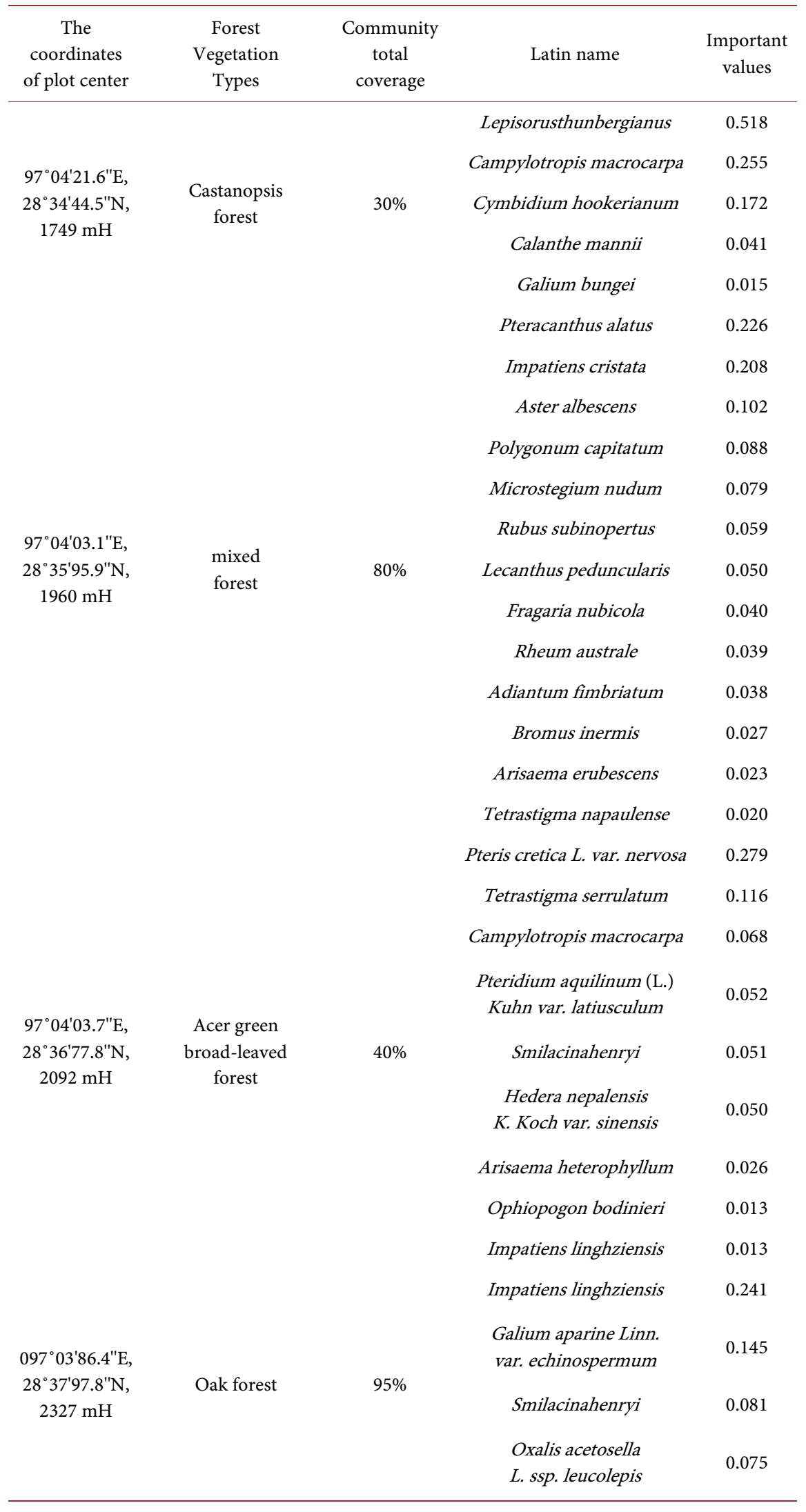




\section{Continued}

\begin{abstract}
$97^{\circ} 04^{\prime} 95.2^{\prime \prime} \mathrm{E}$ $28^{\circ} 71^{\prime} 80.0^{\prime \prime} \mathrm{N}$ $2670 \mathrm{mH}$
\end{abstract}

$97^{\circ} 02^{\prime} 20.5^{\prime \prime} \mathrm{E}$ $28^{\circ} 75^{\prime} 66.0^{\prime \prime} \mathrm{N}$ $2880 \mathrm{mH}$ poplar and birch mixed forest

Quercus aquifolioides forest

Arisaema heterophyllum
Viola szetschwanensis
Campylotropis macrocarpa
Smilax china
Pteridium aquilinum (L.)
Kuhn var. latiusculum

Pteris cretica L. var. nervosa

Ophiopogon bodinieri

Parthenocissus semicordata

Panax pseudoginseng

Wall. var. notoginseng

Hedera nepalensis

K. Koch var. sinensis

Fargesia setosa

Oxalis acetosella

L. ssp. leucolepis

Polygonum nepalense

Galium aparine

Linn. var. echinospermum

$80 \%$

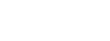

Pilea notata

Impatiens linghziensis
0.075

0.074

0.057

0.051

0.035

0.032

0.031

0.028

0.020

0.012

0.218

0.209

0.181

0.063

0.052

0.051

Parthenocissus semicordata

0.050

Angelica paeoniifolia

0.043

Fragaria nubicola

0.043

Pteridium aquilinum (L.)

Kuhn var. latiusculum

0.030

Fragaria nubicola

Pteridium aquilinum(L.) Kuhn var. latiusculum

Panax pseudoginseng Wall. var. notoginseng

0.140

$90 \%$

Impatiens linghziensis

0.107

Dysosma tsayuensis $\quad 0.050$

Smilax china

0.045

0.026

Pteracanthus alatus, Impatiens cristata, Aster albescens, important values were 0.226, 0.208, 0.102; at an altitude of $2092 \mathrm{~m}$ Acer green broad-leaved forest, plant total the coverage was only $40 \%$ and species number was 9 , the important value of Pteris cretica L. var. nervosa and Tetrastigma serrulatum, were 0.279 and 
0.116; the elevation of $2670 \mathrm{~m}$ poplar and birch mixed forest, plant total coverage is $80 \%$, the number of species was 10, higher important value for Fargesia setosa, Oxalis acetosella L. ssp. leucolepis, Polygonum nepalense, important values were $0.218,0.209,0.181$; at an altitude of $2880 \mathrm{~m}$ in Quercus aquifolioides forest, plant total coverage is $90 \%$, higher important value for Fragaria nubicola, Pteridium aquilinum (L.) Kuhnvar. latiusculum, Panax pseudoginseng Wall. var. notoginseng, Impatiens linghziensis, important values were 0.332, 0.199, 0.140, 0.107 .

\subsection{Species Diversity of Plant Species in Different Elevations of the Cibagou Nature Reserve}

Using Menhinick richness index and Margalef abundance index to analysis, the evaluation of richness from Figure 1, you can see, at an altitude of $1749 \mathrm{~m}$ to $2880 \mathrm{~m}$ range, species richness are low, the overall showed a trend of rise before they are lower; The Shannon-wiener index and Simpson index of different elevation gradient undergrowth species diversity were analyzed (see Figure 2), the results show no obvious difference change with altitude gradient, only at an altitude of $2327 \mathrm{~m}$ diversity is relative taller; The Pielou evenness and Sheldon index of different elevation gradient plant species evenness were analyzed (see Figure 3 ), the results show kindness and ditch undergrowth evenness first decreases after rising trend on the whole. Overall, at an altitude of $2327 \mathrm{~m}$ and an altitude of $2670 \mathrm{~m}$ in plant species richness is relatively high, at an altitude of $2327 \mathrm{~m}$ in species diversity is relatively high, at an altitude of $2670 \mathrm{~m}$ species evenness, lowest possible reasons for the actual survey, at an altitude of $2327 \mathrm{~m}$ and 2670 $\mathrm{m}$ number appears more rare species.

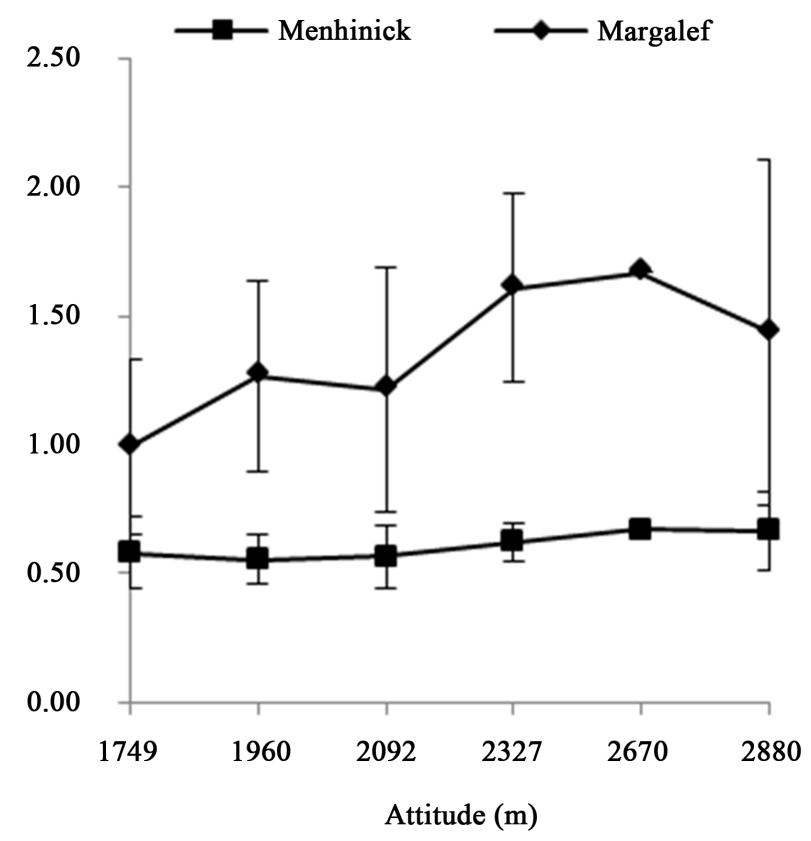

Figure 1. Plant richness in different altitude gradients. 


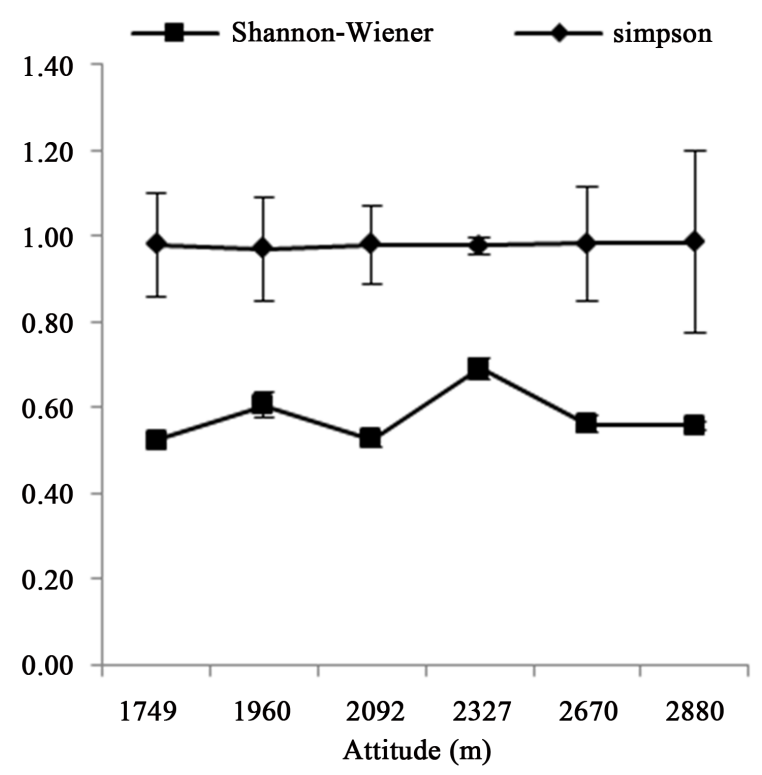

Figure 2. Diversity of plant species at different altitudes.

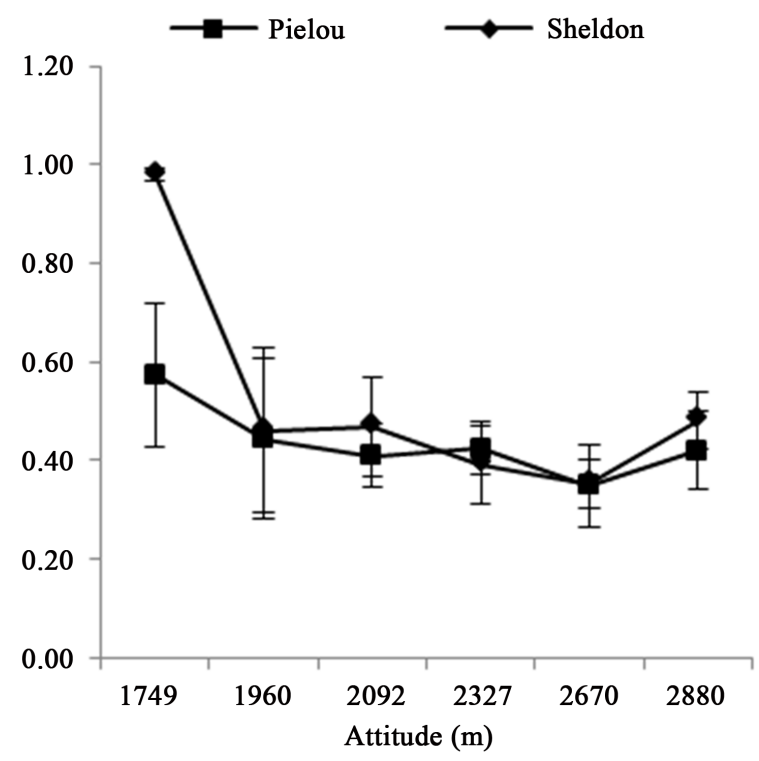

Figure 3. Plant species uniformity at different altitudes.

\section{Discussion}

Community as an important part of biodiversity, species diversity is the very important content in community ecology; altitude is one of the main plant community species composition control mountains natural gradient, elevation gradient change will lead to the change of factors such as temperature, precipitation, light conditions, thus affecting species distribution. Species diversity and the relationship between the altitude gradient has no unified conclusion, species diversity gradually lower approximation with altitude in the change of latitude gradient model has been proved in many mountains [13] [14]. The species diversity of zonal plant communities in western Yunnan was studied and results 
showed that the density of species decreased with the increasing of altitude gradient [15], Zhang [16] also has a consistent conclusion based on Luya Mountain plant community diversity in Shanxi province. However, there are many studies have shown that the temperature and humidity of the elevation in the range has most species survival conditions, thus presents the species richness increased with altitude showed a trend of unimodal curve change [17] [18], namely lower after rising first. Grytnes [19] found that high species richness values appeared at an altitude of 1500 - 2500 min the Himalayas or Nepal. In the study of plant community pattern in Haba Snow Mountain, Yunnan, the peak of herbaceous plant abundance appeared at an altitude of $3000 \mathrm{~m}-3500 \mathrm{~m}$ [20]. The study of the Altai Mountains in Xinjiang also showed that the abundance and diversity of herbaceous plants showed a single peak Curve increases [21]. The reason may be that the study did not include a complete elevation gradient, that is, the peak of the species diversity was not studied in the study of altitudinal gradient [22]. Su [23] have shown that the Tibetan Sejila Mountain herbal plant richness was a double peak curve; about $3500 \mathrm{~m}$ above sea level and an altitude of $4500 \mathrm{~m}$ are high.

The results showed that the species richness of understory plants in Cibagou Nature Reserve increased first and then decreased with the increase of altitude gradient, showing a trend of single peak curve and peak appeared between the attitude $2327 \mathrm{~m}$ - $2670 \mathrm{~m}$, Shannon-wiener diversity index peak appeared at an altitude of $2327 \mathrm{~m}$. The diversity of plant species in different forest plants is relatively large, but the variation of plant diversity varies with altitude and is generally low. Possible reason was the primeval forest nature reserves is relatively complete, tall trees and high shrubs level obviously, lead to light in a certain extent become limiting factors of the growth of undergrowth, at an altitude of 1749 $\mathrm{m}$ is most obvious, the undergrowth only $30 \%$ of the total coverage, with altitude gradient rise, different forest types of forest thinning, forest light penetration enhancement, undergrowth coverage increased significantly, species richness and diversity were slightly rising trend, and with the higher altitude, temperature may become a limiting factor of plant growth, thereby limiting the part of the plant's growth.

\section{Acknowledgements}

This study was financially supported by follow fund: Collection and utilization of medicinal flower resources in Tibet; Research on Tibet resources plant information system based on Android (2015XZ01G28); Fund of Tibet science and Technology Department (2016ZR-NQ-09); Humanities and social science projects in Universities in Tibet (sk2015-36).

\section{References}

[1] Gao, X., Ma, K. and Chen, L. (2001) Species Diversity of Some Deciduous BroadLeaved Forests in the Warm-Temperate Zone and Its Relations to Community Stability. Acta Phytoecologica Sinica, 25, 283-290. 
[2] Lan, S. (2003) Plant Species Diversity in Wuyishan National Nature Reserve. Scientia Silvaesinicae, 39, 36-43.

[3] Hao, Z., Zhao, S. and Tao, D. (1994) Species Diversity and Its Seasonal Dynamics or Herbs in a Broad-Leaved Korean Pine Forest on the Northern Slope of the Changbai Mountain. Chinese Biodiversity, 2, 125-132.

[4] Hao, Z., Zhang, J., Song, B., et al. (2007) Vertical Structure and Spatial Associations of Dominant Tree Species in an Old-Growth Temperate Forest. Forest Ecology \& Management, 252, 1-11. https://doi.org/10.1016/j.foreco.2007.06.026

[5] Condit, R., Ashton, P., Bunyavejchewin, S., et al. (2006) The Importance of Demographic Niches to Tree Diversity. Science, 313, 98.

https://doi.org/10.1126/science.1124712

[6] Wu, P. (2003) Large and Medium-Sized Animals in the Cibagou Nature Reserve. Chinese Journal of Wildlife, 24, 44-46.

[7] Wu, P. and Zhang, E. (2006) Habitat Selection of takin (Budorcastaxicolor) in Cibagou Nature Reserve of Tibet, China. Acta Theriologica Sinica, 26, 152-158. (In Chinese)

[8] Wu, P.J., Zhang, H. and Zhang, E.D. (2007) Vertical Distribution and Habitat Differentiation of Main Artiodactyls in Tibet Cibagou Nature Reserve of China in Spring. Chinese Journal of Ecology, 26, 1569-1573.

[9] Tang, X. and Lu, J. (2011) Diversity and Faunal Analysis of Known Insect Species in Cibagou National Nature Reserve. Journal of Mountain Agriculture and Biology, 30, 487-491. (In Chinese)

[10] He, J., Yue, H. and Zhang, G. (2010) Diversity and Bioactivity Analysis of Actinomycetes Isolated from Cibagou Nature Reserve Soil. Journal of Northwest A\&F University, No. 8, 83-89. (In Chinese)

[11] Zhang, J. (2004) Quantitative Ecology. The Science Publishing Company, Beijing, 77-96.

[12] Deng, L. and Zhang, W. (2010) Natural Development Pattern of Robinia pseudoacacia Plantations in Loess Hilly Region. Scientia Silvaesinicae, 46, 15-22. (In Chinese)

[13] Wilson, J.B., Lee, W.G. and Mark, A.F. (1990) Species Diversity in Relation to Ultramafic Substrate and to Altitude in Southwestern New Zealand. Plant Ecology, 86, 15-20. https://doi.org/10.1007/BF00045131

[14] Wang, Z. and Tang, Z.J. (2007) Altitudinal Patterns of Seed Plant Richness in the Gaoligong Mountains, South-East Tibet, China. Diversity \& Distributions, 13, 845854. https://doi.org/10.1111/j.1472-4642.2007.00335.x

[15] Feng, J. and Xu, C. (2009) Geographical Distribution Patterns of Zonal Plant Community Species Diversity in West Yunnan, China. Chinese Journal of Ecology, 28, 595-600. (In Chinese)

[16] Zhang, L., Zhang, F. and Shang, G. (2000) Vegetation Diversity of Luya Mountains. Chinese Biodiversity, 8, 361-369. (In Chinese)

[17] Sanchez-Gonzalez, A. and Lopez-Mata, L. (2005) Plant Species Richness and Diversity along an Altitudinal Gradient in the Sierra Nevada, Mexico. Diversity \& Distributions, 11, 567-575. https://doi.org/10.1111/j.1366-9516.2005.00186.x

[18] Zhao, C.M., Chen, W.L., Tian, Z.Q., et al. (2005) Altitudinal Pattern of Plant Species Diversity in Shennongjia Mountains, Central China. Journal of Integrative Plant Biology, 47, 1431-1449. https://doi.org/10.1111/j.1744-7909.2005.00164.x

[19] Grytnes, J.A. and Vetaas, O.R. (2002) Species Richness and Altitude: A Comparison 
between Null Models and Interpolated Plant Species Richness along the Himalayan Altitudinal Gradient, Nepal. The American Naturalist, 159, 294.

[20] Tao, J., Zan, G. and Yu, C. (2011) Altitudinal Patterns of Plant Communities and Species Diversity in the Habaxueshan Mountains, Yunnan, China. Scientia Silvae Sinicae, 47, 1-6. (In Chinese)

[21] Jing, X., Zang, R. and Ding, Y. (2010) Distribution Pattern of Species Diversity along Altitudinal Gradient in the Northern Slope of Xiaodonggou in Altai Mountains, Xinjiang. Scientia Silvae Sinicae, 46, 23-28.

[22] Rahbek, C. (2006) The Elevational Gradient of Species Richness: A Uniform Pattern? Ecography, 18, 200-205. https://doi.org/10.1111/j.1600-0587.1995.tb00341.x

[23] Su, J., Liu, W. and Zhang, W. (2011) Species Diversity of Plant Communities along an Altitudinal Gradient on the West Slope of Sejila Mountains, Tibet. Scientia Silvae Sinicae, 47, 12-19. (In Chinese)

\section{Submit or recommend next manuscript to SCIRP and we will provide best} service for you:

Accepting pre-submission inquiries through Email, Facebook, LinkedIn, Twitter, etc. A wide selection of journals (inclusive of 9 subjects, more than 200 journals)

Providing 24-hour high-quality service

User-friendly online submission system

Fair and swift peer-review system

Efficient typesetting and proofreading procedure

Display of the result of downloads and visits, as well as the number of cited articles

Maximum dissemination of your research work

Submit your manuscript at: http://papersubmission.scirp.org/

Or contact ajps@scirp.org 